\title{
THE VOICE OF CONSERVATION-RESTORATION ON MULTI-DISCIPLINARY RESTORATION PROJECTS
}

RØSKAR Tanja ${ }^{1}$

${ }^{1}$ Conservator/advisor, Multiconsult, Rigedalen 15, 4626 Kristiansand, Norway; tanja.roskar@multiconsult.no https://orcid.org/0000-0002-3404-8067

ABSTRACT: As conservator-restorers we should be „a voice of reason”, an advocate that speaks for the cultural heritage values of our built heritage. However, we are often only one voice in a large group consisting of everything from structural engineers, geologists and carpenters to economic advisors and bureaucrats. Being a conservator-restorer in such settings often turns out to be a great balancing act. On the one hand, we are supposed to protect the buildings against any intervention that will compromise its authenticity and cultural values. On the other hand, we must allow as much protective work as possible to ensure the buildings' future. Questions that can arise for a conservator-restorer during and after discussions in multi-disciplinary groups are many. Questions that needs answering before work starts. Are the conservator-restorer and the master craftsperson really on each end of the scale in a project, or is it just that we use different words? Is it conservation ethics versus the practical view of the engineer, or can both sides be pragmatic and find a new and possibly better solution? Is it possible that the conservator-restorer and the funding body can meet in the middle, or can that jeopardize the project?

KEYWORDS: Building restoration, multi-disciplinary work, conservation-restoration, conservationrestoration ethics, cooperation

\section{Conservator-restorer or architect? Craftsman or engineer?}

In comparison with the conservation of objects in museums the conservation-restoration of buildings have traditionally not been thought of as an area where one would naturally find a conservator-restorer, not in the project group and definitely not as the project leader. This has changed in recent years although for many it is still an initial thought that an architect should lead the conservation-restoration of a building. 
Building conservation involves many people: Architects have to act as team directors, as the actual conservation process requires the work of many professionals.

(Muñoz Viñas, 2005, p. 73)

There is also amongst some professionals an unspoken hierarchy where the university trained put themselves above the craftsmen. This is also true within conservation-restoration; many resent any element of their professional education being compared to an apprenticeship or their expertise being described as craftsmanship. (Ashley-Smith, 2016, p. 122)

To lead a successful conservation-restoration project with as few "bumps in the road" as possible the thought of superiority or preconceived ideas that one profession is better to lead a project should be put aside. A successful project is one that is based on dialog, an understanding of the other professions' ethical principles, a respect for each of the different disciplines and inclusion in the planning from the start. Moreover, why not a conservator-restorer in lead of a building restoration project?

\section{One of many voices}

Conserving and restoring buildings are in many areas different from the conservation-restoration of objects, but apart from the sheer size of the object, the scope of the project is the same. Simplified it starts with research and planning, continues with the decision-making and actual work, and ends with a completed project and a report.

In most building conservation-restoration, there will be multiple disciplines involved. In one project, there can be everything from a conservator-restorer to a demolition expert involved. Projects can include structural engineers, architects, carpenters, bricklayers, electricians and conservator-restorers.

Questions that can arise for a conservator-restorer during and after discussions in multi-disciplinary groups are many. Questions that needs answering before work starts. Are the conservator-restorer and the craftspeople really on each end of the scale in a project, or is it just that we use different words? Is it conservation ethics versus the practical views of the engineer, or can both sides be pragmatic and try to together find a new and possibly better solution to a problem? Is it possible that the conservatorrestorer and the funding body can meet in the middle, or can this jeopardize a project?

Working in the field of building conservation-restoration one constantly balances between technical principles and conservation principles, and since most of the buildings are in use and/or being lived in it is necessary to be a pragmatic conservator-restorer.

When the projects are far away from the office, the conservator-restorer cannot always be a constant presence. In many multi-disciplinary projects there is usually only one conservator-restorer involved, and problems will often have to be solved on the spot, whether the building is old or new, small or large, made of wood or brick. Decisions must then be a combined effort from all disciplines involved where each discipline will have to respect the principles others are working out of.

This is a reality that very few conservation-restoration schools and courses prepare their students for, working out in the field where decisions must be made on the spot, in cooperation with disciplines that are very different from your own and there is no time for a decision- or work analysis-flow chart. 


\section{Three building restoration projects}

Conservation-restoration is governing by the principles of minimal intervention, the use of appropriate materials and - as far as possible - reversible methods, and a full documentation of all work undertaken. These principles are fully adaptable to building conservation-restoration and working with other professions in multi-disciplinary groups. The key element is dialog and making sure everyone are on common ground when it comes to vocabulary and understanding of the project.

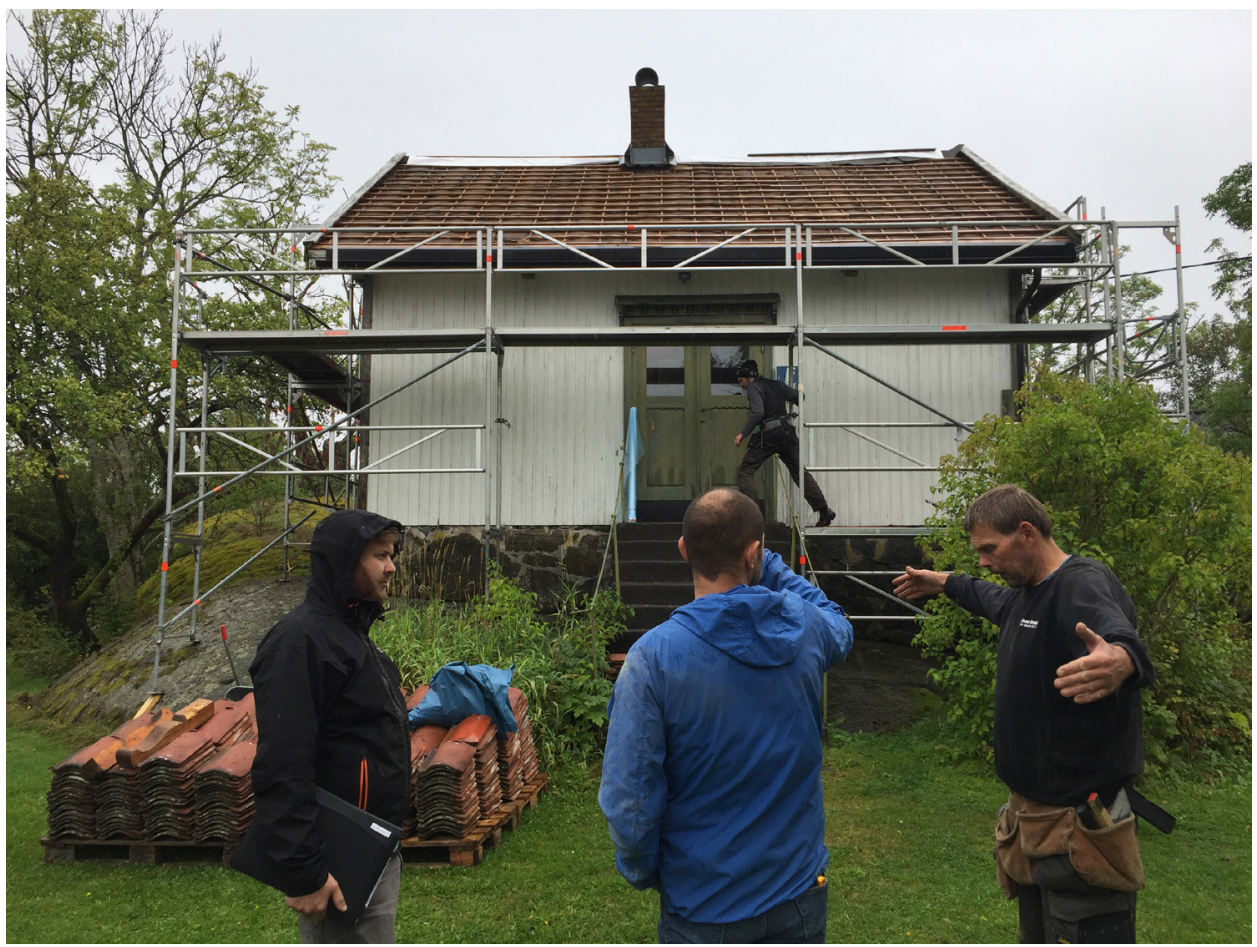

Fig. 1 Conservator-restorer or architect? The restoration of buildings requires many people, and just as the conservation-restoration of smaller objects in a museum, it requires planning and preparation. Photo: Tanja Røskar

In the three cases of building conservation-restoration projects mentioned here, the cooperation between different disciplines went fairly easily. The differences in principles are not that prominent, the basis is very similar, what can be different is profession-specific principles. There are certain principles that are more prominent for conservator-restorers than for other, one is i.e. the ethics of treating objects from other cultures, and another is documentation.

Conservator-restorers are trained to document every stage of any conservation planning and work they undertake. The transferal of this professional habit to other disciplines within a building conservationrestoration project is important and something conservator-restorers need to work towards. A way of ensuring that documentation is a part of a project is to include the following article from the Venice Charter into the project plan: 
In all works of preservation, restoration or excavation, there should always be precise documentation in the form of analytical and critical reports, illustrated with drawings and photographs. Every stage of the work of clearing, consolidation, rearrangement and integration, as well as technical and formal features identified during the course of the work, should be included. This record should be placed in the archives of a public institution and made available to research workers. It is recommended that the report should be published.

(The Venice Charter, 1964, article 16)

\section{Case 1: Stangnes, buildings at the end of a footpath on the edge the sea}

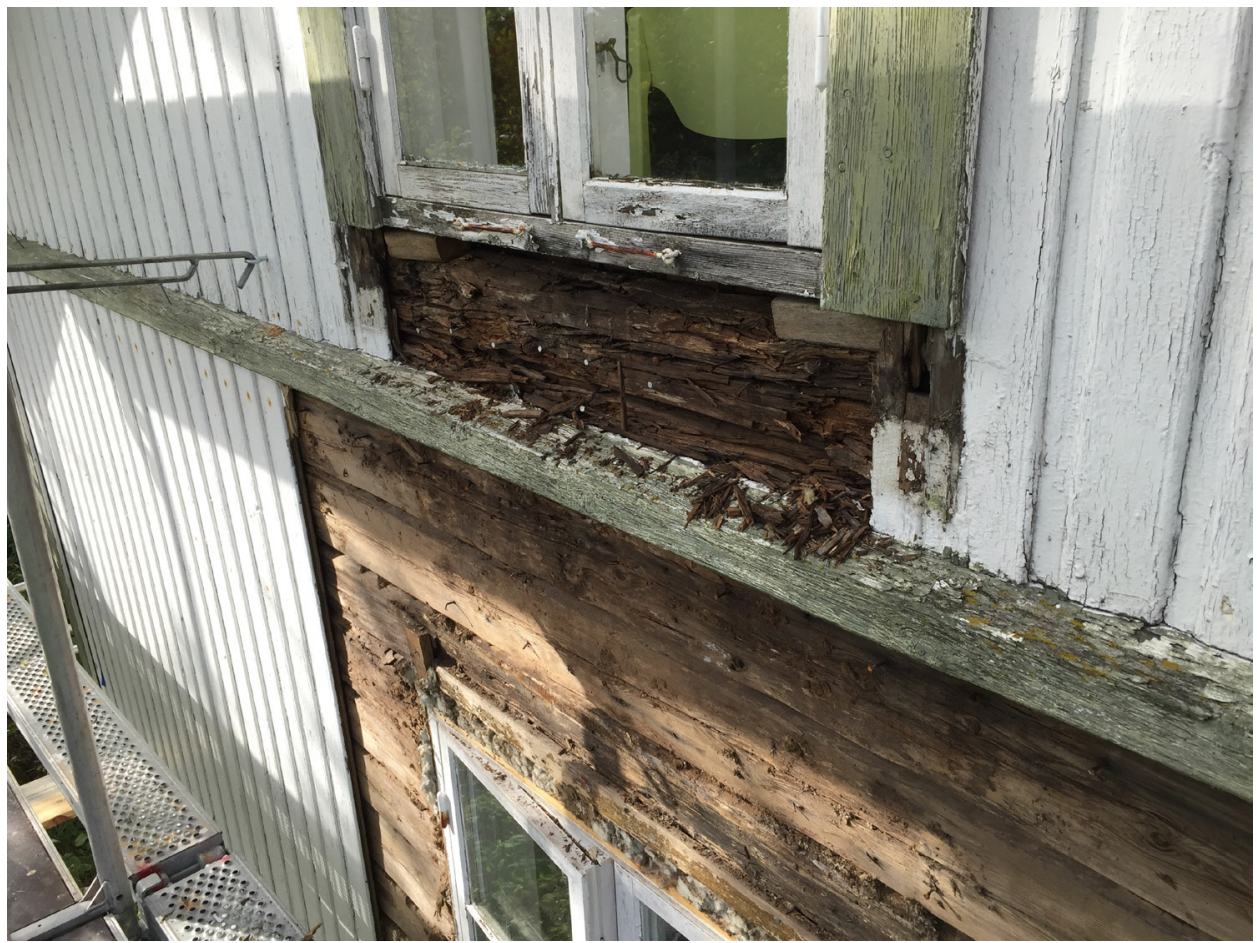

Fig. 2 Sometimes decisions regarding the restoration have to be taken based on photographic evidence and oral reports from people on-site. This requires a common vocabulary and understanding of principles. Photo: Tanja Røskar

The buildings at Stangnes are situated on the edge of a peninsula with only a very narrow and winding footpath leading up to the buildings. To complicate matters more there are laws protecting both the cultural and natural heritage of the site as it sits in a national park. The conservation-restoration project has involved the local council, a government directorate, a building restoration firm, a window restorer, painters, a restorer of antique ovens and a conservator-restorer.

In preparation for the conservation-restoration of the buildings, consultants wrote an extensive condition report with treatment plan and costs. This report is the work order for the restoration firm. The work has been prolonged extensively though due to unexpected problems that have surfaced. 
In unexpected situations, like when removing panelling exposed much more rot than expected, it is important that the conservator-restorer (who was not on-site) and craftspeople share a common work vocabulary and have agreed upon the principles before work started. As mentioned in this project there was a very extensive work plan that was also thoroughly gone through word by word by all involved parties. This was done to make sure that everyone had the same understanding of the plan and the conservation-restoration principles the craftspeople had to work by since the conservator has only been present on project meetings or when asked to come to discuss and assess a new problem/ area.

\section{Case 2: Barthebrygga 14, restoring the only remaining 17th century room left in a building}

The scope of this conservation-restoration was to preserve the old storeroom on the ground floor of an old pack house, now residential home. To save the building and foundations, and the storeroom, it was necessary to remove the ground floor floorboards and dig out soil and sand and lay down gravel to better the drainage and ground conditions. In this project a master craftsman and several craftspeople, a conservator-restorer and an engineer (the owner) was involved.

As with Stangnes this project also benefitted from an extensive plan for the work, in this case made by the engineer. Also, as with Stangnes, the project manager, in this case the engineer, could not be onsite for most of the project, but the conservator-restorer was on hand for discussions.

The close dialog between the craftsman, engineer and conservator-restorer ensured that the work followed closely principles of conservation set out by i.e. English Heritage.

- The historic environment is a shared resource

- Everyone should be able to participate in sustaining the historic environment

- Understanding the significance of places is vital

- Significant places should be managed to sustain their values

- Decisions about change must be reasonable, transparent and consistent

- Documenting and learning from decisions is essential

(English Heritage, 2008) 

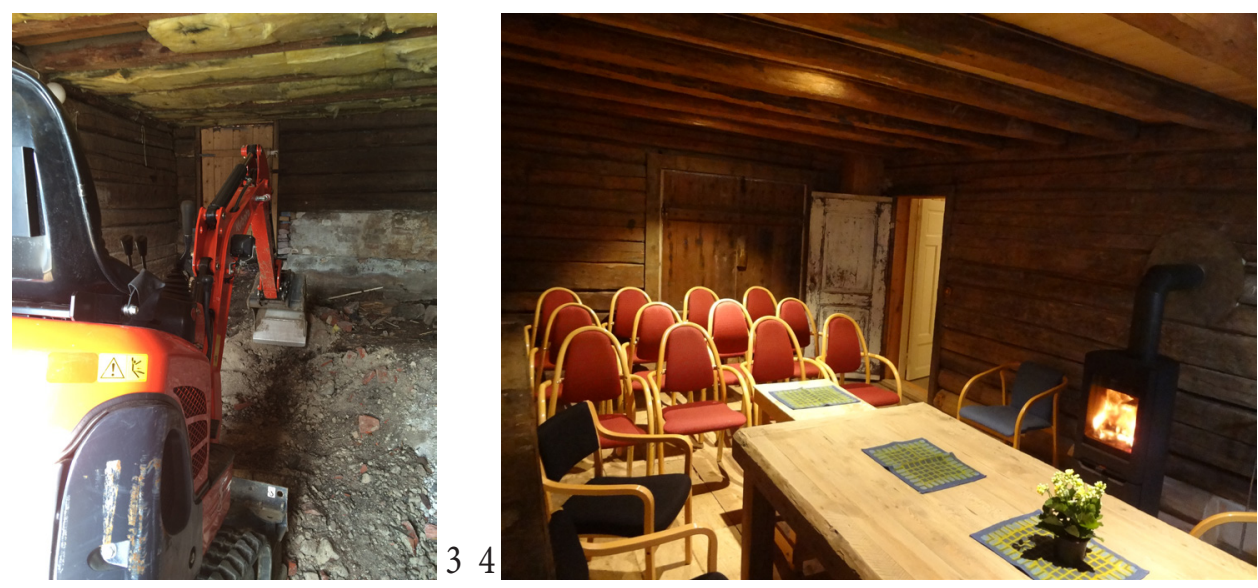

Fig. 3 Most conservators are more used to the scalpel or the cotton swab, but when working with buildings a mini-digger is not an uncommon tool to be seen during a project. Here the ground underneath a 17th century floor had to be dug out and replaced to improve drainage and prevent raising damp that was threatening the building. Photo: Jonny Jensen AS

Fig. 4 The finished restored room seen in the last picture with the mini-digger. Photo: Tanja Røskar

The conservation-restoration of the storeroom at Barthebrygga 14 proved successful from a conservator-restorer's point of view as the interest for doing the work according to conservationrestoration principles increased as the project went along. The close cooperation between master craftsman, conservator-restorer and engineer also resulted in technical solutions that are adapted to the needs of the building.

\section{Case 3: Enghavehuset, a building restoration project in an open-air museum}

The conservation-restoration of Enghavehuset at the Aust-Agder Museum and Archive was a large project that included two project leaders, one consultant dealing with the economy and contracts and a conservator-restorer that was leading the planning and practical conservation-restoration work.

This was a large project with a multi-disciplinary working group consisting of eight different professions. There were amongst others carpenters, bricklayers, landscape architects, engineers and demolition experts. 


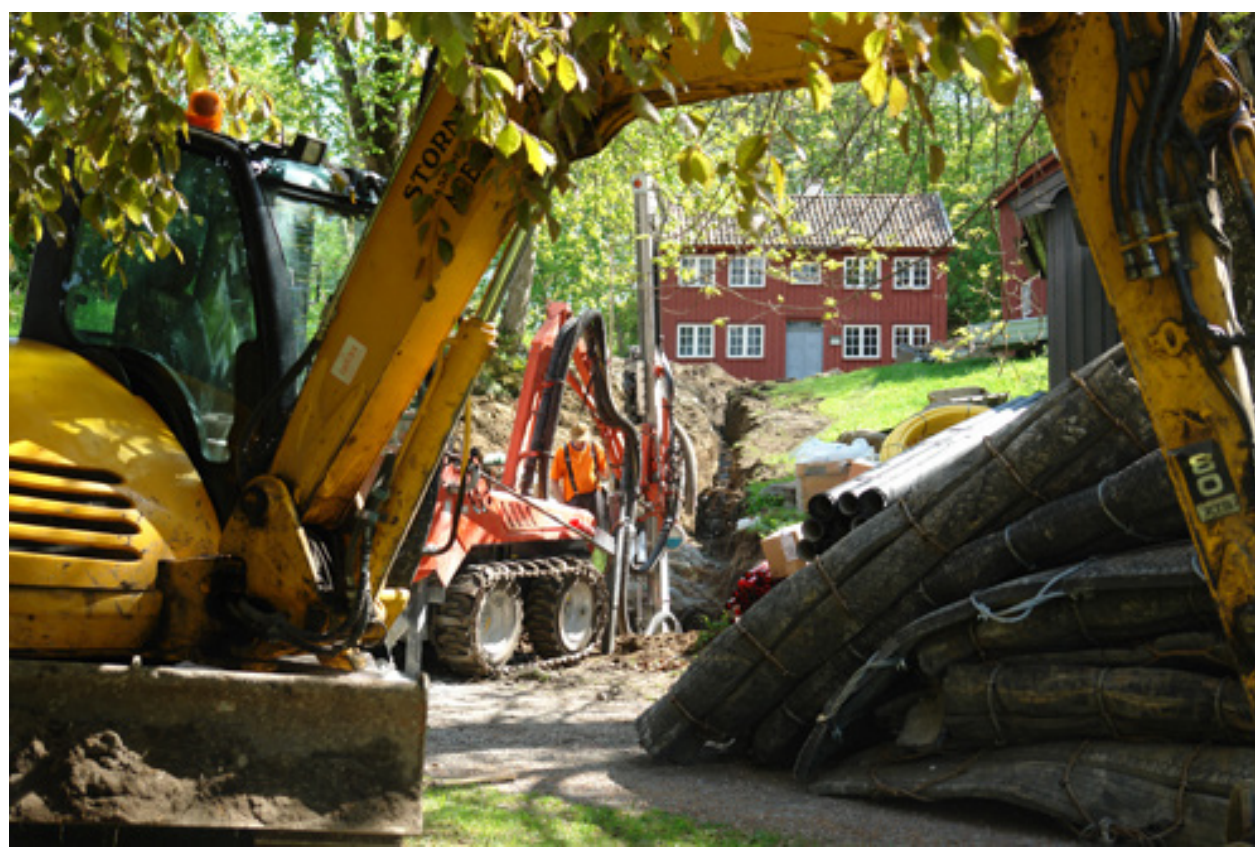

Fig. 5 The restoration of Enghavehuset required a project group consisting of eight different professions, with everything from conservator to demolition expert. All in all, this little house had apx. 15 people working on different aspects of the restoration during the project. Photo: Tanja Røskar

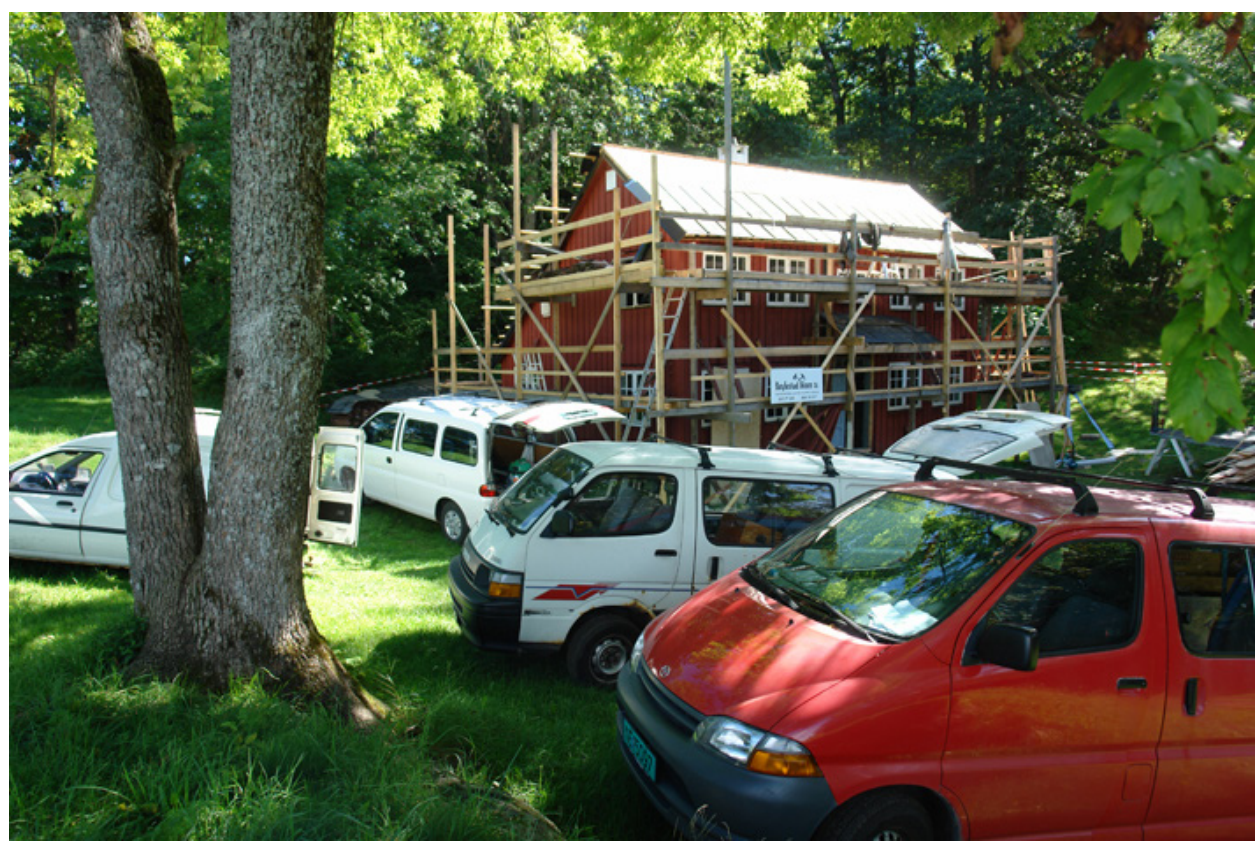

Fig. 6 On any given day there could be 4-5 different types of craftspeople present on-site. This resulted in a parking problem that was larger than any cooperation problems. Photo: Tanja Røskar 
The project was put out to tender and to make sure that potential tenderers understood the principles of building conservation-restoration in a museum setting a presentation was made which included the history of the building before and after it ended up in the open-air museum. This way it was hoped that they understood the heritage values of the building as well as the technical aspects. In the presentation, we also pointed out what parts that were not to be touched. Some of these parts were self-evident, but others was maybe a bit more difficult to understand for non-experts, such as preserving the small holes in one of the walls from air gun pellets shot by a protesting neighbour.

This project was the first large building conservation-restoration in which I had the project leadership. Working with so many different professions, I found a recipe for leading multi-disciplinary projects that I have been following since (Røskar, 2010):

- Gather information - drawings, photos, archive material etc. before making a project description/ plan.

- Make a presentation to prospective craftsmen/companies if the job is to be put out to tender.

- Have very specific work orders and be prepared to explain your decisions.

- Explain your conservation-restoration principles, but also respect their professional principles.

- Stand firm, but be pragmatic.

- Follow up, be present on the site or come by when it is required.

- Remember that no profession is above another, we are all just as important in getting the job done.

- Do what conservator-restorers do better than most - document!

\section{Everything is a story}

Throughout discussions with different stakeholders on small or large building conservation-restoration projects, I have always found that early dialog and inclusion of everyone involved from the start has been alpha and omega for a successful project. It is also important that everyone involved understands where the other part is coming from, professionally.

And although we conservator-restorers might like to think so, it is not always crystal clear to others why we want to preserve certain structures or objects. During a project last year I had to argue extensively with both owners and craftsmen that a table from the 1960-70s with 50 or so years of teenage carvings such as „I love Dr. Dre” was just as important as the dates carved on the original 1880s beams inside the walls. In the end, I won them over with my simple conclusion borrowed from a painted street art wall: Everything is a story. 


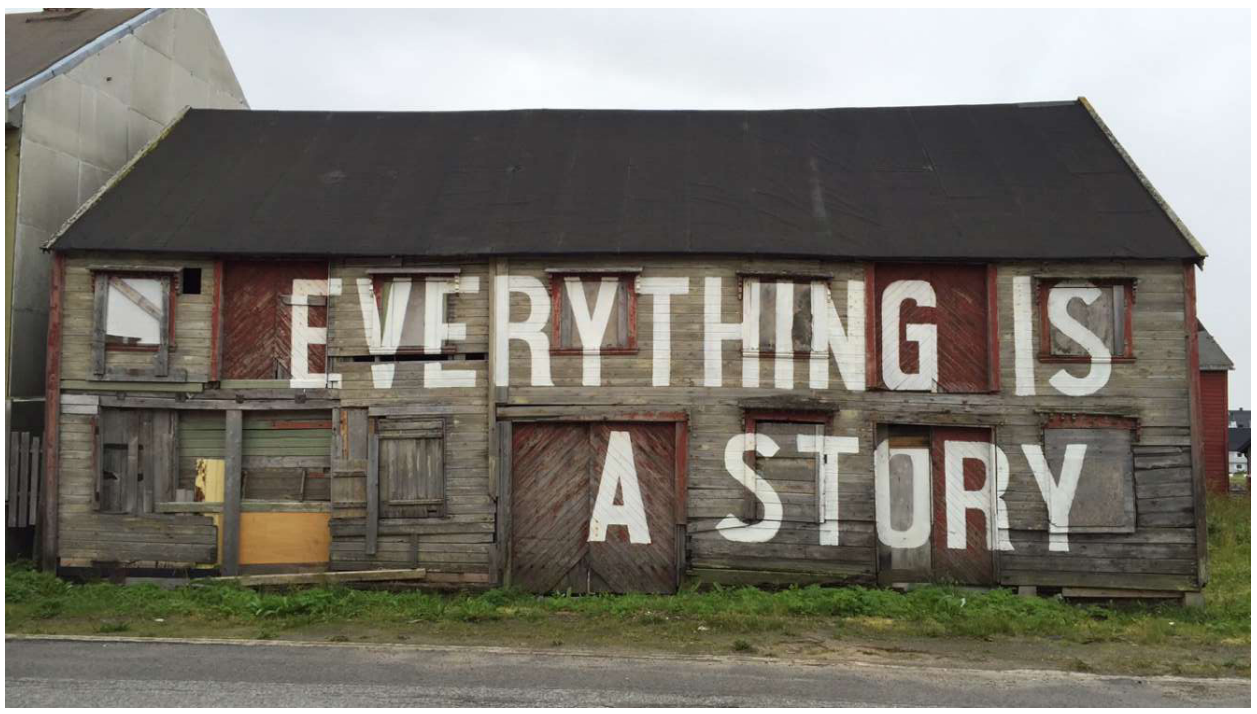

Fig. 7 Remember - „Everything is a story” - there is a story behind every change in material, every damage and every addition made. (Artwork by E.B. Itso). Photo: Tanja Røskar

\section{Bibliography}

Ashely-Smith, J. (2016). Losing the edge: the risk of a decline in practical conservation skills. Journal of the Institute of Conservation, volume 39, pp.119-132.

English Heritage (2008). Conservation principles policies and guidance for the sustainable management of the historic environment. English Heritage.

Muñoz Viñaz, S. (2005): Contemporary Theory of Conservation. Oxford: Elsevier ButterworthHeinemann.

Røskar, T. (2010). Enghavehuset - restaurering av hus og hage. Aust-Agder museet. Internal report.

The Venice Charter. International Charter for the Conservation and Restoration of Monuments and Sites (1964). In: MONUMENTA I, Internationale Grundsätze und Richtlinien der Denkmalpflege/ Principes et directives internationaux pour la conservation/International Principles and Guidelines of Conservation (pp. 47-52), herausgegeben von/édités par/edited by ICOMOS Deutschland, ICOMOS Luxemburg, ICOMOS Österreich, ICOMOS Schweiz (2012). Stuttgart: Fraunhofer IRB Verlag. 
